\title{
Quality loss of spring-harvested fresh ginseng under simulated export and distribution conditions
}

\author{
Eun Ha Chang ${ }^{1}$, Yeoung Seuk Bae ${ }^{2 *}$, Ji Hyun Lee ${ }^{1}$, Il Sheob Shin ${ }^{1}$, Ji Weon Choi ${ }^{1}$ \\ ${ }^{1}$ Postharvest Research Division, National Institute of Horticultural and Herbal Science, Wanju 55365, Korea \\ ${ }^{2}$ Ginseng Division, Department of Herbal Crop Research, National Institute of Horticultural and Herbal Science, \\ Eumseong 27709, Korea
}

\section{봄 수확 수삼의 모의수출 유통 조건에서 환경별 품질 손실유형}

\author{
장은하 ${ }^{1} \cdot$ 배영석 $^{2 *} \cdot$ 이지현 ${ }^{1} \cdot$ 신일섭 $^{1} \cdot$ 최지원 ${ }^{1}$ \\ ${ }^{1}$ 국립원예특작과학원 저장유통과, ${ }^{2}$ 국립원예특작과학원 인삼과
}

\begin{abstract}
We investigated the causes of quality loss of fresh ginseng during simulated export by air and ship. Fresh ginseng was washed and packed in large (5 kg) or small $(500 \mathrm{~g})$ functional low-density polyethylene (LDPE) film packages. The packages were then stored under a range of temperatures, to simulate various export conditions. For export by air, the storage temperatures were $15^{\circ} \mathrm{C}$ and $25^{\circ} \mathrm{C}$, for 4 days. For export by ship, the storage temperatures were $1{ }^{\circ} \mathrm{C}$ and $5^{\circ} \mathrm{C}$, for 14 days. At the conclusion of the export simulation experiment, ginseng was stored at $10^{\circ} \mathrm{C}$ to simulate distribution conditions. We found that loss under simulated export was mostly through softening and decay due to fungal infection. The time point at which the combined loss from softening and decay due to fungal infection reached $20 \%$ was considered the limit of distribution. Following air export simulation at $25^{\circ} \mathrm{C}$, ginseng in the large and small LDPE film packages lasted for 10 days and 6-7 days, respectively, whereas after air export simulation at $15^{\circ} \mathrm{C}$, it lasted for 17 days and 12-13 days in the large and small packages, respectively. Following ship export simulation at $5^{\circ} \mathrm{C}$, ginseng in the large and small packages lasted for 21 days and 28 days, respectively, whereas after ship export simulation at $1^{\circ} \mathrm{C}$, it lasted for 24 days and 29 days in the large and small packages, respectively. The fungi responsible for the loss of fresh ginseng quality were mostly Fusarium sp., Botrytis sp., and Penicillium sp. The dominant strain at $25^{\circ} \mathrm{C}$ was Fusarium sp., whereas Botrytis sp. was dominant at lower temperatures.
\end{abstract}

Key words : functional film, fungus, postharvest, rot, spore

\section{서 론}

인삼 재배 면적은 2010년 19,010 ha에서 2016년 14,679 ha로 감소하고 있다. 국내 인삼 생산량 20,386 톤(2016년 기준) 중 국내에서 소비되는 소비량은 15,151 톤으로 $72 \%$ 수준이다. 그러나 국내의 다양한 건강기능성 식품의 소비

*Corresponding author. E-mail : ysbae63@korea.kr Phone : 82-43-871-5603, Fax : 82-43-871-5509

Received 21 June 2018; Revised 27 August 2018; Accepted 31 August 2018.

Copyright (c) The Korean Society of Food Preservation. All rights reserved.
증가는 인삼의 소비 감소를 초래하여 원료삼의 재고량이 증가하고 있는 추세이다. 인삼 품목별 국내 소비 형태는 홍삼 $61.8 \%$, 수삼 $34.8 \%$, 백삼 $2.6 \%$ 를 차지하고 있다. 수삼 은 시장의 수요에 따라 봄, 여름, 가을, 초겨울에 주로 수확 하며, 관행적으로 봄(2-3월) 및 초겨울(11-12월)에 수확한 수삼은 3 개월, 가을(9-10월)에는 1 개월, 여름(7-8월)에는 2 주간 저장 유통이 가능한 것으로 알려져 있다.

국내 수삼은 주로 대형 골판지 상자에 넣어 도매시장으 로 유통되어 포장하지 않고 채(또는 차, $750 \mathrm{~g}$ ) 단위로 소매 되거나, 수확 후 선별과정을 거쳐 규격에 따라 약 $75 \mathrm{~kg}$ 혹은 그 이상의 단위로 포장하며, 속포장지로 polyethylene 필름 $(100 \mu \mathrm{m})$ 을, 겉포장지로 골판지 상자를 이용하여 포장 
한다. 대단위 포장 시 내부의 호흡열 발생 및 압착 등은 물리적 손상을 유발하며, 저장 중 품질 저하의 주요 요인이 된다. 이런 이유로 수삼은 수확 후 $5^{\circ} \mathrm{C}$ 이하 온도에서 강제 송풍 또는 수분 분무 조건에서 예냉 처리를 하기도 한다. 수확 된 수삼의 저장은 대부분 $0^{\circ} \mathrm{C}$ 이하의 저온에서 저장하 는데 수삼의 동결점은 $-1.5^{\circ} \mathrm{C}$ 내외로 대부분 수삼의 저장고 는 동결점보다 낮은 $-2^{\circ} \mathrm{C}--4^{\circ} \mathrm{C}$ 를 유지하고 있으며, 저장 중 동해 및 과습 등에 따른 손실이 발생한다.

또한 수삼의 유통은 흙이 묻은 대단위 포장 상태로 저온 에 저장하다 출하 시 세척·포장을 하므로 유통 시 조직이 물러지고 부패가 쉽게 발생하므로 이와 같은 문제를 방지하 기 위한 다양한 유통방법에 대한 연구가 진행되어 왔다. 수삼의 수확 후 저장 중 발생하는 병해 연구가 보고되었고 (1), 기존 수확 후 흙이 묻어 있는 수삼의 저장 - 유통 방식의 개선 방법에 대한 연구가 수행되었다(2). 수삼의 신선도 연장을 위한 연구로는 controlled atmosphere(CA) 및 modified atmosphere(MA) 저장에 관한 연구가 수행되었다 $(3,4)$. 특히 CA 저장 시 미생물 증식 억제, 내공(cavitation) 경감 등의 장점이 있고, 최적 $\mathrm{CA}$ 조건은 $1 \% \mathrm{O}_{2}+>5 \% \mathrm{CO}_{2}$ 로 보고하였다(4,5). 수삼의 필름 포장 연구로는 $\mathrm{Kim}$ 등(6)과 Sohn 등 $(7,8)$ 이 수행하였고, Kim 등(9)과 Chang 등(10)은 저장온도에 따른 수삼의 내부 품질 변화에 관한 연구를 수행하였다. 수삼의 신선도 유지 및 저장성 연장을 위한 화학적 처리 연구로는 1-methylcyclopropene 처리 효과(11) 및 세척 수삼의 포장 전 2-phenylethy alcohol의 훈증 효과 연구가 수행되었다(12). 또한 수삼 수확에서 판매에 이르기 까지 품질저하의 잠재 요인을 파악하기 위한 저장관리 실태 와 유통현황에 관한 연구 등이 수행되었다(13).

최근 동남아시아, 중동 등을 중심으로 국내 수삼에 대한 수요가 증가하고 있으나 수출 현장에서 수확 후 품질관리 기술이 부족하여 대량 수출이 곤란하다. 따라서 인삼의 수 출을 촉진하기 위해서는 인삼의 수확 시기별, 유통환경별 품질변화에 대한 연구가 필요하며, 특히 인삼의 수출 환경 에서 발생하는 부패의 주요 원인을 파악하는 것이 필요하여 본 실험을 수행하였다.

\section{재료 및 방법}

\section{실험 재료 및 모의수출 유통 조건}

본 실험에 사용한 재료는 2017년 3월에 충남 금산에서 재배된 개체 당 중량과 크기가 균일한(수삼 한 개체 당 $48.9 \pm 5.0 \mathrm{~g}$, 길이 $28.0 \pm 2.9 \mathrm{~cm}$, 중심주 너비 $2.0 \pm 0.2 \mathrm{~cm}$ ) 4년근 수삼(직삼)을 수확하여 이용하였으며, 수확 후 실험 실로 옮겨 $18^{\circ} \mathrm{C}$ 를 유지하는 세척실에서 고압분무세척과 건조 후 대포장과 소포장으로 포장하였다(Fig. 1). 사용한 포장재는 다공성물질인 제올라이트와 페그마이트가 $5 \%$
함유된 LDPE $50 \mu \mathrm{m}$ 필름(기능성 $\mathrm{LDPE}$ 필름)을 사용하였 다. 소포장 조건은 기능성 $\mathrm{LDPE}$ 필름 $(30 \times 40 \mathrm{~cm})$ 에 수삼을 $500 \mathrm{~g}$ 씩 넣고 골판지 박스에 넣어 포장하였으며, 대포장 조건은 기능성 $\mathrm{LDPE}$ 필름 $(70 \times 90 \mathrm{~cm})$ 에 수삼을 $5 \mathrm{~kg}$ 씩 넣고 골판지 박스에 넣어 포장하였다. 수삼 수출은 동남아시아 지역을 고려하여 항공과 선박 2 수준의 운송조건으로 모의 수송 온도 및 기간을 설정하였다. 모의수출 유통 온도 조건 중 소포장의 항공 조건은 15 및 $25^{\circ} \mathrm{C}$ 저장고에 4 일 둔 뒤 $10^{\circ} \mathrm{C}$ 로 옮겨 유통하는 온도로 설정하였고, 선박 조건은 1 및 $5^{\circ} \mathrm{C}$ 저장고에 14 일 둔 뒤 $10^{\circ} \mathrm{C}$ 에서 유통하는 온도로 설정하였다. 대포장의 모의수출 유통 온도 조건은 항공과 선박 조건 모두 소포장과 동일하게 수행하였고, 수삼의 품 질조사는 세척·건조 후 포장된 날부터 시작하였다.

\section{포장 내 기체조성}

포장 내 $\mathrm{O}_{2}$ 및 $\mathrm{CO}_{2}$ 측정은 $\mathrm{O}_{2} / \mathrm{CO}_{2}$ 가스분석기(PBI Dansensor, CheckMate9900, Ringsted, Denmark)를 이용하 여 측정하였다.

\section{수삼의 모의수출 유통 중 손실 유형 조사}

수삼의 모의수출 유통 중 손실 유형을 조사하기 위해 각 모의유통 온도별 물러짐, 부패, 뇌두 출아를 조사하였고 손실률은 전체 개체 수에 대한 백분율로 나타내었다(Fig. 2). 출아 여부는 수삼의 뇌두 부분에 싹 발아가 일어나 줄기 까지 확연하게 자란 것들의 길이를 측정하고 전체 개체수에 대한 출아개수를 백분율로 나타내었다. 물러짐과 부패도 측정은 0 에서 4 단계로 나누어 0 단계는 곰팡이 발생이나 물러짐이 전혀 눈으로 감지할 수 없는 단계, 1 단계는 뇌두부 분에 곰팡이 균사체를 정밀하게 관찰해야 보이는 단계로 판매에는 지장이 없는 단계, 2 단계는 뇌두와 세근에 곰팡이 나 무름이 눈으로 관찰되는 단계, 3 단계는 곰팡이나 짓무름 이 생겼으나 그 부분을 제거하면 식용가능 단계, 4단계는 곰팡이 발생이나 물러짐이 심해 판매 불가능 단계로 나누어 전체 조사 개체 수에 대한 백분율로 나타내었다. 모의수출 유통 수삼의 한계 손실률은 2 단계부터 4단계까지 각 온도 별 손실률을 조사하여 20\%에 도달하는 기간으로 나타내었 다.

\section{수삼 모의수출 유통 중 부패 원인균 분리 및 동정}

수삼의 모의수출유통 중 온도별 부패에 관여하는 병원균 을 분리 및 동정하였다. 모의수출 유통 중 수삼의 부패 원인 병원균의 분리는 부패한 수삼으로부터 건전부위와 부패부 위의 경계 부분의 조직 $(1 \times 1 \mathrm{~cm}$ 이하 크기)을 무균적으로 채취하여 $70 \%$ 에탄올 및 $1 \% \mathrm{NaOCl}$ 용액을 이용하여 표면 을 살균하였다. 표면 살균한 조직은 멸균수로 세척한 다음 풍건하고 준비된 water $\operatorname{agar}(\mathrm{WA})$ 상에 올려놓고 $25^{\circ} \mathrm{C}$ 배양 기에서 보관하면서 자라나온 균사를 무균적으로 potato 


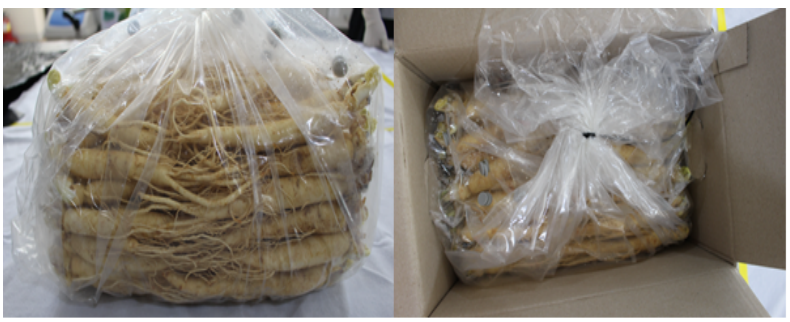

Fresh ginseng packaged with $5 \mathrm{~kg}$

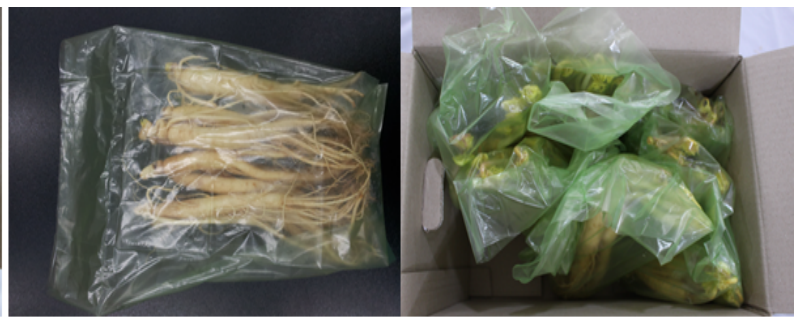

Fresh ginseng packaged with $500 \mathrm{~g}$

Fig. 1. Appearance of fresh ginseng packaged with $5 \mathrm{~kg}$ and $500 \mathrm{~g}$ during storage under simulated export conditions and distribution.
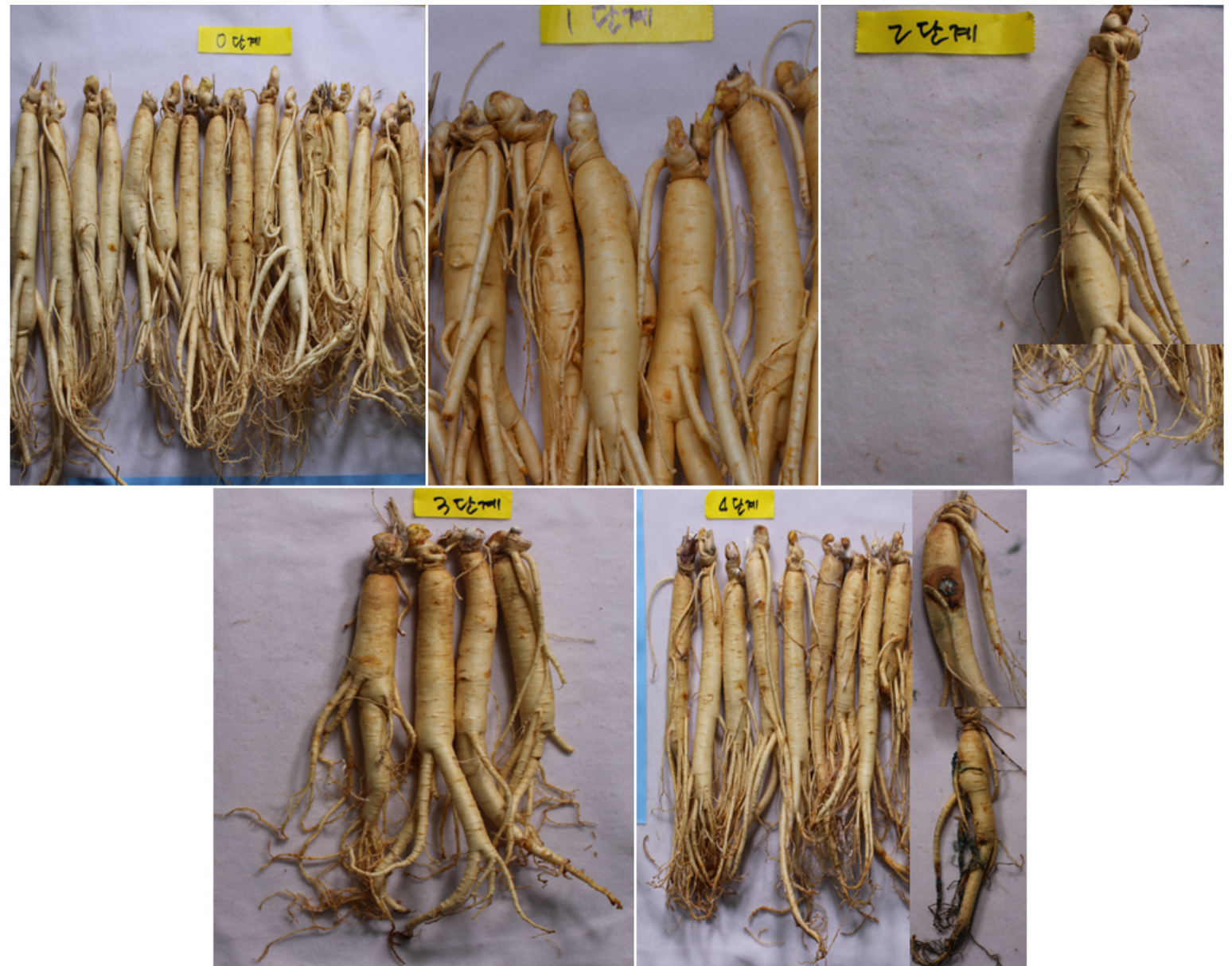

Fig. 2. Grade of quality loss types during storage under simulated export conditions and distribution.

Stage 0, step that does not occurrence mold or soft rot; Stage 1, step of recognizing that the mycelium of mold is closely observed at the head of ginseng; Stage 2, step of observing the mold and soft rot on the root and head of ginseng; Stage 3, step that can be eaten if the mold or soft rot occurred, but the part is removed; Stage 4, unsalable step.

dextrose agar(PDA)에 옮겨 순수 분리하였다. 순수 분리한 곰팡이는 광학현미경하에서 형태적 특성을 관찰하여 수삼 의 토양전염병 병원곰팡이의 그림책들과, compendium, monogrape, 기타 실험 매뉴얼들을 참고하여 속(genus) 단위 의 분류동정을 수행하였고, 종(species) 단위의 분류동정은 Snyder-Hansen 방식의 분류 시스템(Nelson-Toussoun-Marasas) (14)과 Nirenberg(15) 및 Gerlach-Nirenberg(16) 방식으로 분류
하였다. 형태적인 특징의 현미경 관찰은 주로 대형포자 (macroconidia), 소형포자(microconidia), 후벽포자 (chlamydospores), philides(conidiophores)를 PDA, WA에 배 양한 후 관찰하였다. 배지에 우러나는 색깔(color diffused into agar)의 조사는 주로 PDA 배양으로 하였으며, 색깔의 유무, 혹은 옅음(color absent or pale) 및 carmine red 색깔, purple 색깔을 나타내는 것들은 주로 Snyder과 Hansen(14) 
방법으로 판별하였다. 기중 균사의 유무, slimy, yeast-like colony형성(Eupionnotes), 매우 천천히 자라는 균(growth very slow) 등의 특징을 조사하여 분류하였다. 분리빈도는 분리한 전체 균주 중 병원균별 균주수를 계산하여 백분율로 나타내었다.

\section{통계분석}

수삼의 모의수출 유통 중 포장 내 기체조성, 병원균 분리 및 동정, 병원성 검정과 손실유형 평가는 3-4 반복씩 조사하 여 평균값을 구한 후 표준편차(standard deviation, SD)로 나타내었다.

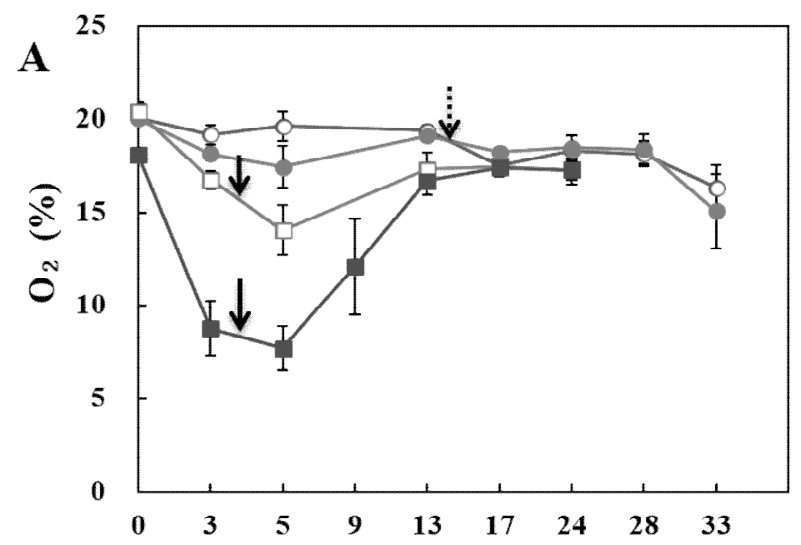

Days after packaging for simulated export

\section{결과 및 고찰}

\section{포장 내 기체조성}

포장재 내의 기체조성은 시료의 호흡률과 포장재의 기체 투과도에 의해 결정된다(17). 수삼의 모의수출 유통 중 포장 재 내의 기체조성 변화를 측정한 결과를 각각 Fig. 3과 Fig. 4에 나타내었다. Fig. 3 은 $5 \mathrm{~kg}$ 대포장의 수삼을 항공 모의수 출 조건인 $25^{\circ} \mathrm{C}$ 와 $15^{\circ} \mathrm{C}$ 에 두었을 때 5 일까지 두 온도조건에 서 모두 $\mathrm{O}_{2}$ 농도가 감소하였다. 특히 $25^{\circ} \mathrm{C}$ 모의수출 유통 온도에서 3 일에 $8 \%$ 까지 $\mathrm{O}_{2}$ 농도가 급격히 감소하다가 $10^{\circ} \mathrm{C}$ 유통 온도로 옮긴 후 포장재 내 $\mathrm{O}_{2}$ 농도가 증가하기 시작하 여 유통 13일 이후는 16.7-17.3\%까지 비슷한 수준의 $\mathrm{O}_{2}$

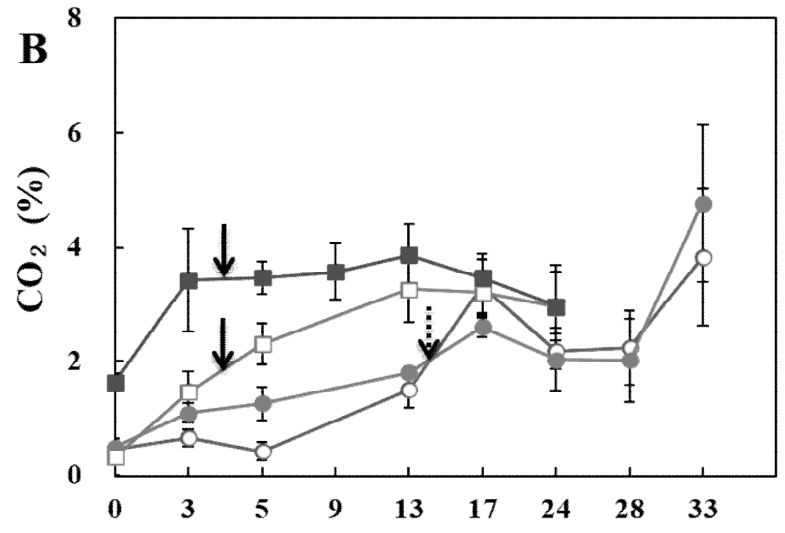

Days after packaging for simulated export

Fig. 3. Changes in $\mathrm{O}_{2}(\mathrm{~A})$ and $\mathrm{CO}_{2}$ (B) concentrations of fresh ginseng packaged with $5 \mathrm{~kg}$ during storage under simulated export conditions and distribution at $10^{\circ} \mathrm{C}$.

, $25^{\circ} \mathrm{C}$ simulated export conditions by air transport; $\square, 15^{\circ} \mathrm{C}$ simulated export conditions by air transport; $0,5^{\circ} \mathrm{C}$ simulated export conditions by ship transport; $\bigcirc, 1^{\circ} \mathrm{C}$ simulated export conditions by ship transport.

$\downarrow\left(25^{\circ} \mathrm{C}\right.$ and $\left.15^{\circ} \mathrm{C}\right), \downarrow\left(1^{\circ} \mathrm{C}\right.$ and $\left.5^{\circ} \mathrm{C}\right)$ meaning the day of distribution at $10^{\circ} \mathrm{C}$.

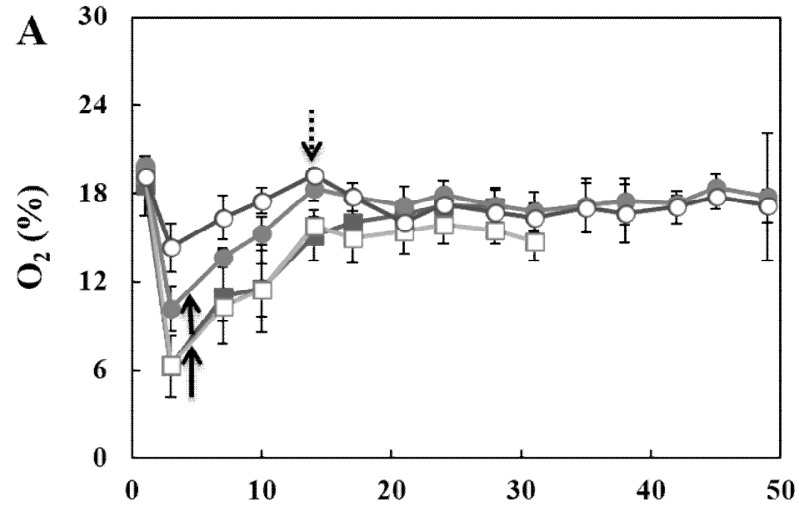

Days after packaging for simulated export

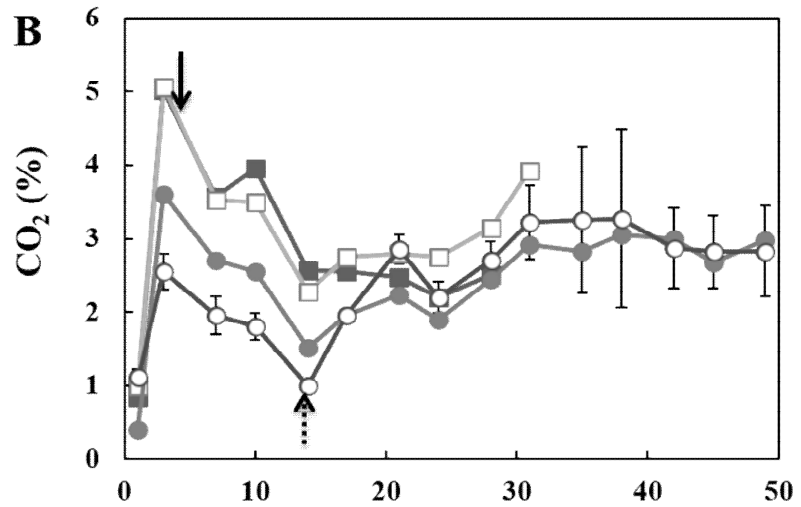

Days after packaging for simulated export

Fig. 4. Changes in $\mathrm{O}_{2}$ (A) and $\mathrm{CO}_{2}$ (B) concentrations of fresh ginseng packaged with $500 \mathrm{~g}$ during storage under simulated export conditions and distribution at $10^{\circ} \mathrm{C}$.

$25^{\circ} \mathrm{C}$ simulated export conditions by air transport; $\square, 15^{\circ} \mathrm{C}$ simulated export conditions by air transport; simulated export conditions by ship transport.

$\downarrow\left(25^{\circ} \mathrm{C}\right.$ and $\left.15^{\circ} \mathrm{C}\right), \quad\left(1{ }^{\circ} \mathrm{C}\right.$ and $\left.5^{\circ} \mathrm{C}\right)$ meaning the day of distribution at $10^{\circ} \mathrm{C}$. 
농도를 유지하였다. 선박 모의수출 조건인 $1^{\circ} \mathrm{C}$ 와 $5^{\circ} \mathrm{C}$ 의 온 도에 둔 후 $10^{\circ} \mathrm{C}$ 유통 온도로 옮긴 수삼의 $\mathrm{O}_{2}$ 농도는 $1^{\circ} \mathrm{C}$ 보 다 $5^{\circ} \mathrm{C}$ 의 경우 초기부터 서서히 감소하기 시작하여 총 유통 기간 28일에 17.5-18.2\%까지 감소한 뒤 이후 좀 더 감소하 여 15-16\%까지 $\mathrm{O}_{2}$ 농도가 감소하였고, $1^{\circ} \mathrm{C}$ 에서는 초기와 비슷한 $20 \%$ 의 $\mathrm{O}_{2}$ 농도를 유지하다 $10^{\circ} \mathrm{C}$ 유통 시 감소하여 $17.5-18.2 \%$ 의 농도를 유지하다 이후 좀 더 감소하여 $16 \%$ 의 $\mathrm{O}_{2}$ 농도를 나타내었다. $\mathrm{CO}_{2}$ 농도는 항공 모의수출 조건인 $25^{\circ} \mathrm{C}$ 와 $15^{\circ} \mathrm{C}$ 의 온도에 둔 기간에 농도가 증가하는데 $25^{\circ} \mathrm{C}$ 의 경우 3 일에 $3.5 \%$ 까지 증가한 후 비슷한 농도를 유지하다 13 일 이후 감소하였고, $15^{\circ} \mathrm{C}$ 는 13 일까지 $3.3 \%$ 농도까지 증가한 이후 약간 감소하는 경향을 보였다. 선박 모의수출 유통 조건인 $1^{\circ} \mathrm{C}$ 와 $5^{\circ} \mathrm{C}$ 의 온도에 둔 수삼에서는 유통 중 농도가 서서히 증가하기 시작하여 유통 28 일에 $2 \%$ 까지 증가하였으나 이후 33 일에 급격한 $\mathrm{CO}_{2}$ 농도가 포장재 내에 서 감지되어 4-5\% 농도까지 증가하였다.

Fig. 4 에서 $500 \mathrm{~g}$ 소포장의 경우 항공 모의수출 유통 조건 인 $25^{\circ} \mathrm{C}$ 와 $15^{\circ} \mathrm{C}$ 의 온도에 둔 후 $10^{\circ} \mathrm{C}$ 에서 유통한 수삼의 포장재 내 기체조성 중 $\mathrm{O}_{2}$ 의 농도는 초기 19.0-20\%에서 3 일이 지난 뒤 $6 \%$ 까지 감소하였다가 이후 증가하기 시작하 여 유통 14일 이후에는 15-17\% 농도를 유지하였다. 선박 모의수출 조건인 $1^{\circ} \mathrm{C}$ 와 $5^{\circ} \mathrm{C}$ 의 $\mathrm{O}_{2}$ 농도는 초기에 $19.1-20 \%$ 의 $\mathrm{O}_{2}$ 농도에서 유통 3 일에 $5^{\circ} \mathrm{C}$ 는 $10 \%, 1^{\circ} \mathrm{C}$ 는 $14 \%$ 농도까지 감소하였다가 이후 $\mathrm{O}_{2}$ 농도가 증가하기 시작하여 유통 17 일에는 $17 \%$ 의 농도로 증가한 뒤 유통 50 일까지 거의 일정 한 농도를 유지하였다. 선박 모의수출 유통 조건인 $1^{\circ} \mathrm{C}$ 와 $5^{\circ} \mathrm{C}$ 에 둔 수삼의 포장 내 $\mathrm{O}_{2}$ 소모가 항공유통 조건인 $25^{\circ} \mathrm{C}$ 와 $15^{\circ} \mathrm{C}$ 에 둔 수삼보다 초기에는 적지만 14 일 후 $10^{\circ} \mathrm{C}$ 동일 유통 조건에서 일정 시간이 경과하면 모든 처리구에서 $17 \%$ 정도의 $\mathrm{O}_{2}$ 농도를 유지하는 것으로 나타났다. $\mathrm{CO}_{2}$ 농도는 $25^{\circ} \mathrm{C}$ 와 $15^{\circ} \mathrm{C}$ 의 경우 $0.85-1 \%$ 의 농도에서 유통 3 일에 $5 \%$ 까 지 증가하였다가 이후 감소하여 유통 30일 경 2.5-3.9\%까지 감소하였다. 선박 조건인 $1^{\circ} \mathrm{C}$ 와 $5{ }^{\circ} \mathrm{C}$ 의 둔 수삼의 $\mathrm{CO}_{2}$ 농도 는 초기 0.4-1\%에서 유통 3일에 2.5-3.6\%까지 증가하였지 만 이후 유사한 농도를 유지하여 유통 50일 경에는 $3.0 \%$ 정도의 $\mathrm{CO}_{2}$ 농도로 나타났다.

본 실험에 사용한 기능성 LDPE 필름은 투과도가 높은필 름으로 수삼 저장 중 초기 온도가 높아도 유통 온도를 $10^{\circ} \mathrm{C}$ 로 일정하게 유지하면 일정 유통 시간이 지나 $\mathrm{O}_{2}$ 농도는 다시 증가하고 반면 $\mathrm{CO}_{2}$ 농도는 감소하여 모든 온도 처리구 에서 비슷한 농도의 포장 내 기체조성을 유지하는 것으로 나타났다. 그러나 초기 온도를 통제하지 못하면 수삼의 부 패로 인해 포장 내 기체 조성은 유통 중 계속 변화하게 될 것으로 판단되는데 대포장의 유통 33 일 경 $\mathrm{CO}_{2}$ 농도가 급격히 증가하는 이유도 수삼 부패에 의한 호흡 상승이나 부패 미생물의 호흡과 같은 영향 때문인 것으로 판단된다.

\section{수삼의 모의유통 중 손실 유형 조사}

수삼의 항공 및 선박의 모의수출 유통 중 손실 유형을 조사하기 위해 모의수출 유통 포장 당일부터 $10^{\circ} \mathrm{C}$ 유통기간 까지 총 기간 손실률 조사를 하였을 때 수삼의 손실률에 가장 크게 영향을 미치는 요인은 물러짐과 곰팡이 발생에 의한 부패, 뇌두부위 출아에 의한 상품가치 하락으로 나타 났다(Fig. 5, Fig. 6). 뇌두부위 출아는 부패에 의한 손실과는 다르지만 상품가치를 하락시키는 원인이 될 수 있다. 수삼 의 뇌두 출아는 봄 수확 수삼과 가을 수확 수삼이 확연히 다른데 본 연구와는 다른 실험을 통해 가을 수확 수삼에서 는 저장기간 뇌두부위 출아는 전혀 발생하지 않았고, 봄 수확 수삼의 경우 수확시기가 늦으면 뇌두 출아가 증가하는 경향을 보였다(data not shown). 수삼의 부패에 의한 손실유

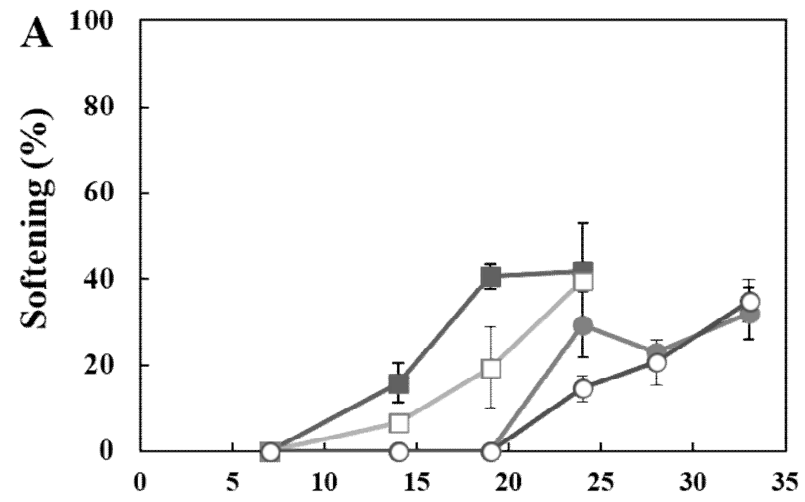

Days after packaging for simulated export

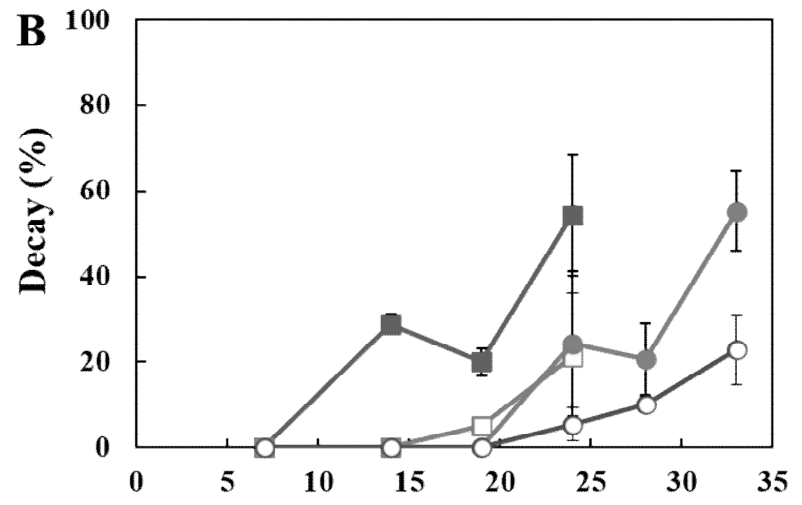

Days after packaging for simulated export

Fig. 5. Softening (A) and decay (B) ratio of fresh ginseng packaged with $5 \mathrm{~kg}$ during storage under simulated export conditions and distribution at $10^{\circ} \mathrm{C}$.

, $25^{\circ} \mathrm{C}$ simulated export conditions by air transport; $\square, 15^{\circ} \mathrm{C}$ simulated export conditions by air transport; simulated export conditions by ship transport. 


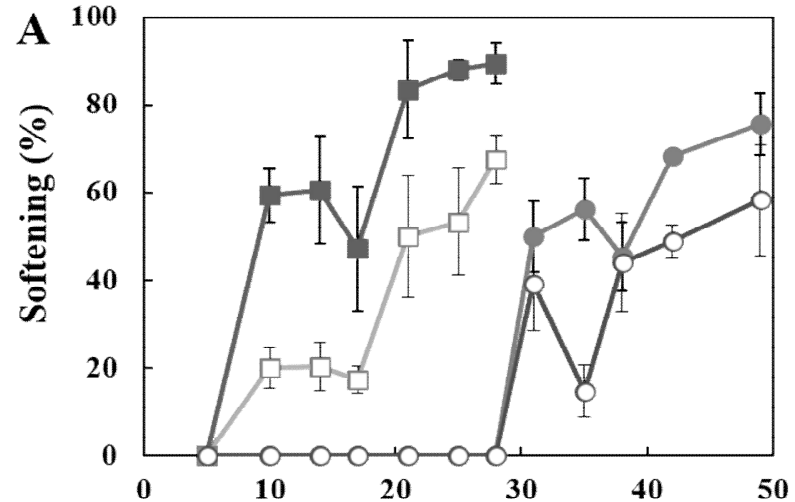

Days after packaging for simulated export

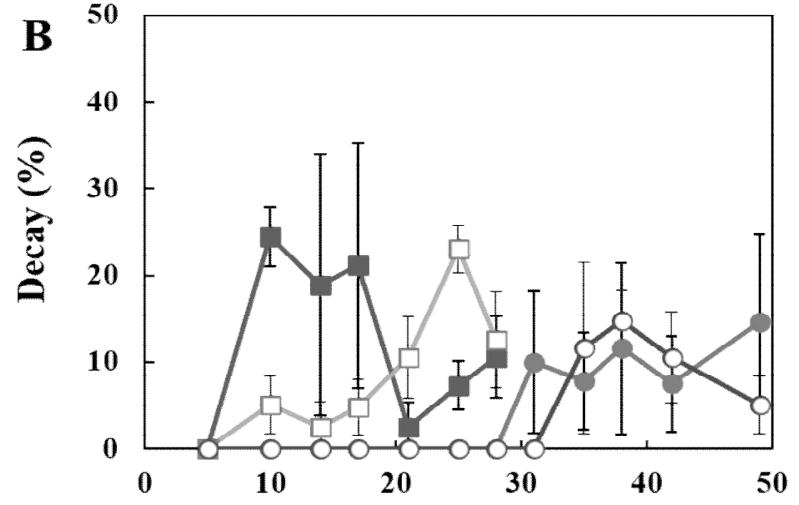

Days after packaging for simulated export

Fig. 6. Softening (A) and decay (B) ratio of fresh ginseng packaged with $500 \mathrm{~g}$ during storage under simulated export conditions and distribution at $10^{\circ} \mathrm{C}$.

, $25^{\circ} \mathrm{C}$ simulated export conditions by air transport; $\square, 15^{\circ} \mathrm{C}$ simulated export conditions by air transport; simulated export conditions by ship transport.

형 중 대포장 항공 모의수출 유통 조건인 $25^{\circ} \mathrm{C}$ 와 $15^{\circ} \mathrm{C}(\mathrm{Fig}$. $5 \mathrm{~A}, 5 \mathrm{~B})$ 는 7일까지 수삼의 물러짐 현상이 없다가 Fig. 5A에 서 보듯이 14 일에 $25^{\circ} \mathrm{C}$ 는 물러짐 현상이 $15.8 \%, 15^{\circ} \mathrm{C}$ 는 $6.6 \%$ 로 나타났고 24 일에는 $40 \%$ 이상 물러짐 현상이 나타 났다. 곰팡이 발생에 의한 부패(Fig. $5 \mathrm{~B})$ 는 $25^{\circ} \mathrm{C}$ 와 $15^{\circ} \mathrm{C}$ 모두 유통 7 일까지 손실률이 발생되지 않다가 $25^{\circ} \mathrm{C}$ 에서 유통 14 일에 $28.8 \%$ 가 나타났으며 24 일에 $50 \%$ 이상의 부패가 나타났다. 4 일 동안 항공 모의수출 유통 후 $10^{\circ} \mathrm{C}$ 유통 중 $15^{\circ} \mathrm{C}$ 는 $25^{\circ} \mathrm{C}$ 보다 물러짐 현상이나 곰팡이에 의한 부패가 덜 발생하였지만 19 일에 $20 \%$ 정도의 물러짐 현상이 발생하 였고, 부패는 24 일에 $20 \%$ 발생하였다. 선박의 모의수출 유통 조건인 $5^{\circ} \mathrm{C}$ 와 $1^{\circ} \mathrm{C}$ (Fig. 5A, 5B)는 유통 19일까지 물러 짐 현상(Fig. $5 \mathrm{~A})$ 이나 곰팡이에 의한 부패(Fig. $5 \mathrm{~B})$ 가 발생 하지 않았다. $5^{\circ} \mathrm{C}$ 의 경우 24 일 경 물러짐이나 부패가 20-30\% 이상 진행되었고 유통 33일에 물러짐은 $30 \%$ 이상, 곰팡이에 의한 부패는 $50 \%$ 이상 발생하였다. $1^{\circ} \mathrm{C}$ 도 물러짐 현상은 24 일 경부터 발생하였으며, 부패는 33 일에 $20 \%$ 이 상 발생하였다.

$500 \mathrm{~g}$ 소포장을 한 수삼의 항공 모의수출 유통 조건인 $25^{\circ} \mathrm{C}$ 와 $15^{\circ} \mathrm{C}$ 에서 손실률을 조사했을 때 포장 개체간 차이가 크지만 전반적으로 대포장보다 물러짐이나 곰팡이 발생에 의한 부패가 더 빨리 진행되는 것으로 나타났다(Fig. 6A, $6 \mathrm{~B})$. 물러짐 현상은 유통 총 기간 중 모든 온도에서 5 일까지 는 나타나지 않았지만(Fig. $6 \mathrm{~A})$ 유통 10 일에 항공 모의수출 유통 조건인 $25^{\circ} \mathrm{C}$ 에서는 $60 \%$ 정도의 물러짐 현상이 나타났 고, 유통 28 일에는 $90 \%$ 의 물러짐 현상이 발생하였다. $15^{\circ} \mathrm{C}$ 에서는 유통 10 일에 $20 \%$ 정도, 유통 28 일에는 $68 \%$ 정도의 물러짐 현상이 발생하였다(Fig. 6A). 선박 모의수출 유통 조건인 $1^{\circ} \mathrm{C}$ 와 $5^{\circ} \mathrm{C}$ 에서는 유통 28 일까지 물러짐 현상이 발생 하지 않았으며 31 일 이후 $1^{\circ} \mathrm{C}$ 와 $5^{\circ} \mathrm{C}$ 에서 각각 $40 \%$ 및 $50 \%$
정도 발생하였다. 곰팡이 발생에 의한 부패(Fig. 6B)는 항공 모의수출 유통 조건인 $25^{\circ} \mathrm{C}$ 에서 유통 10 일에 $25 \%$ 정도 발생하였지만 이후 유통 28 일까지 발생률이 낮은 양상을 보였다. 이는 아마 항공 모의유통 기간 4 일 동안은 $25^{\circ} \mathrm{C}$ 의 온도에 있다가 4 일 이후 $10^{\circ} \mathrm{C}$ 의 유통 온도로 옮기면서 곰팡 이 발생이 상대적으로 낮은 온도에 의해 억제되었거나 포장 내부 기체 조성의 변화가 곰팡이 발생이 불리한 환경으로 작용한 결과 때문인 것으로 판단된다. $15^{\circ} \mathrm{C}$ 의 유통 온도에 서는 유통 10 일에 $5 \%$ 의 부패가 나타났고 이후 서서히 부패 가 진행되어 유통 25-28일에는 20\% 정도 부패가 발생하였 다. 선반 모의수출 유통 조건인 $1^{\circ} \mathrm{C}$ 와 $5^{\circ} \mathrm{C}$ 에서는 28 일까지 곰팡이가 발생되지 않았고, 31 일 경 $5^{\circ} \mathrm{C}$ 에서 $10 \%$ 정도 발생 되다가 이후 50 일까지 $15 \%$ 정도 발생되었다. $1^{\circ} \mathrm{C}$ 는 유통 31 일까지 곰팡이 발생이 일어나지 않았으며 이후 유통 중 $10-15 \%$ 정도 곰팡이에 의한 부패가 발생하였다.

모의수출 유통 중 부패에 의한 손실률을 대포장과 소포 장으로 비교했을 때 소포장의 경우 물러짐 현상이 대포장보 다 훨씬 높게 나타나는 반면 곰팡이 발생에 의한 부패는 대포장보다 낮게 나타났다.

Fig. 7에서는 물러짐과 곰팡이에 의한 부패를 합한 종합 손실률에서 손실률 $20 \%$ 를 유통기한으로 정했을 때 각 모의 유통 온도별 손실률이 $20 \%$ 에 도달하는 기간을 나타낸 그림 이다. 항공 모의수출 유통 조건인 $25^{\circ} \mathrm{C}$ 에서 $5 \mathrm{~kg}$ 대포장은 10 일, $500 \mathrm{~g}$ 소포장은 $6-7$ 일에 $20 \%$ 에 도달했으며, $15^{\circ} \mathrm{C}$ 는 $5 \mathrm{~kg}$ 대포장은 17 일, $500 \mathrm{~g}$ 소포장은 $12-13$ 일에 $20 \%$ 에 도달 했다. 선박 모의유통 조건인 $5^{\circ} \mathrm{C}$ 는 $5 \mathrm{~kg}$ 대포장은 21 일, $500 \mathrm{~g}$ 소포장은 28 일 경에 $20 \%$ 에 도달했고, $1^{\circ} \mathrm{C}$ 는 $5 \mathrm{~kg}$ 대포장은 24일, $500 \mathrm{~g}$ 소포장은 29일 경에 $20 \%$ 에 도달하는 것으로 나타났다. 본 실험을 통해 수삼의 유통은 모의수출 방법뿐 아니라 포장용량도 손실률에 상당한 영향을 미치는 
것으로 나타났는데 결과를 통해 항공유통과 같이 높은 온도 로 단기간에 유통을 해야 하는 경우는 대포장이 수삼의 손실률을 감소시키고, 선박 유통과 같이 저온에서 중·장기 간 유통 시에는 소포장이 손실률을 감소시키는데 효과가 있는 것으로 나타났다. 신선 원예산물의 필름 포장은 자체 $\mathrm{MA}$ 효과를 나타내기 때문에 포장 내 가스 조성 특히 $\mathrm{CO}_{2}$ 의 증가가 곰팡이와 같은 미생물의 발생을 억제시키는데 효과 를 나타내어 유통 초기 $\mathrm{CO}_{2}$ 농도가 좀 더 높은 소포장이
대포장보다 곰팡이 발생이 억제되었을 것으로 판단된다. 물러짐 현상은 압상이나 세균에 의해 발생하는 경우가 많은 데 $5 \mathrm{~kg}$ 대포장보다 $500 \mathrm{~g}$ 소포장에서 물러짐 현상이 많은 이유는 압상에 의한 원인보다 세균 발생에 의한 영향이 높은 것으로 판단된다. 실험을 통해 초기 운송 및 유통 중 온도를 제어하지 못하면 이후 저온의 온도에서 수삼을 유통 시키더라도 물러짐이나 부패는 상당히 많이 또 급속히 진행 되는 것으로 나타나 수확 후 예냉이나 운송 온도를 저온으

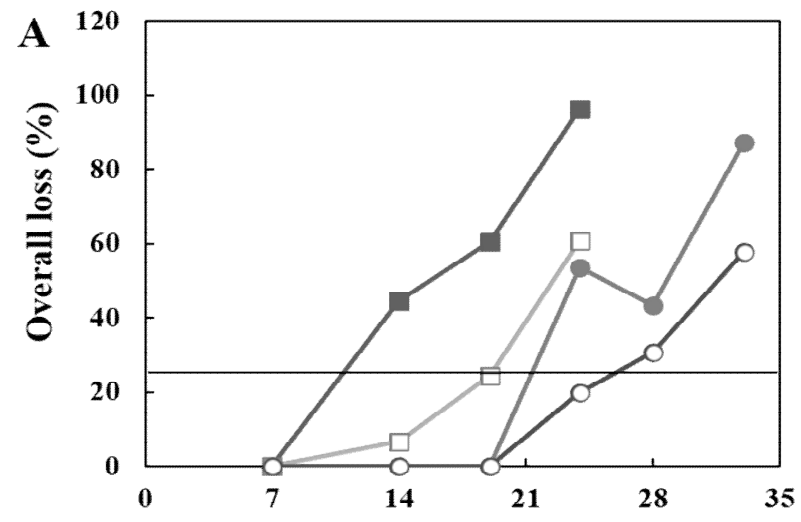

Days after packaging for simulated export

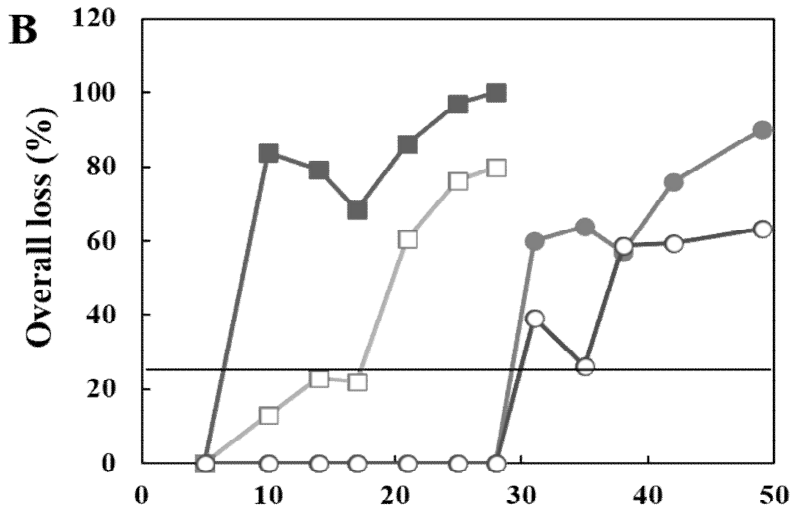

Days after packaging for simulated export

Fig. 7. Overall loss and limit period of fresh ginseng packaged with $5 \mathrm{~kg} \mathrm{(A)}$ and $500 \mathrm{~g}$ (B) during storage under simulated export conditions and distribution at $10^{\circ} \mathrm{C}$.

$25^{\circ} \mathrm{C}$

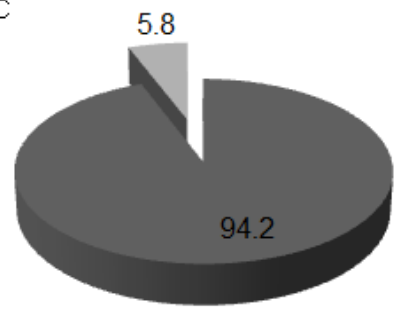

๑ Fusarium घ Unknown

$5^{\circ} \mathrm{C}$

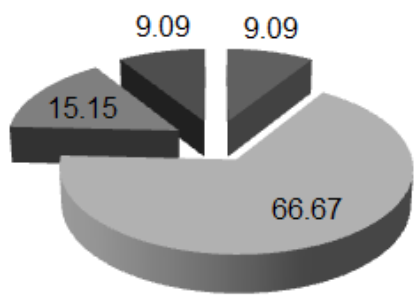

Fusarium $\quad$ Botrytis $15^{\circ} \mathrm{C}$

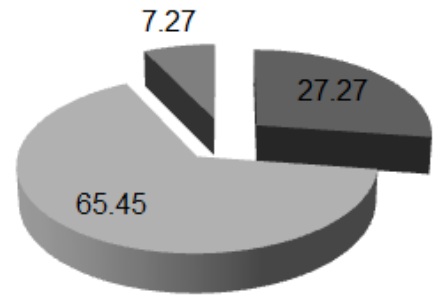

- Fusarium $₫$ Botrytis $\approx$ Penicillium

$1{ }^{\circ} \mathrm{C}$

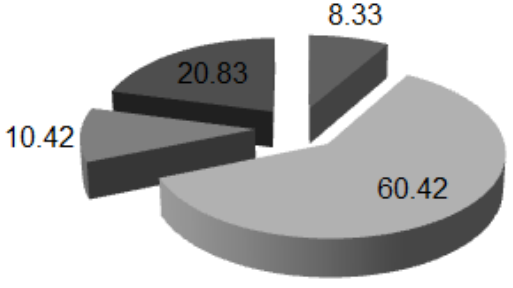

-Fusarium

Botrytis

- Unknown

Fig. 8. Fungal strains involved in the loss of fresh ginseng packaged with $5 \mathrm{~kg}$ during storage under simulated export conditions and distribution at $10^{\circ} \mathrm{C}$. 
로 유지시키는 것이 수삼의 손실율을 줄일 수 있는 방법이 라 판단된다.

\section{수삼 모의유통 중 부패 원인균 분리 및 동정}

수삼의 항공 및 선박의 모의유통 중 손실 유형은 대부분 물러짐과 곰팡이 발생에 의한 것으로 나타났고 곰팡이 발생 중 구체적인 부패 관여 균을 조사하기 위해 균을 분리 및 동정한 결과를 Fig. 8, Fig. 9에 나타내었다. 수삼의 대포장 중 항공 모의수출 유통 조건인 $25^{\circ} \mathrm{C}$ 에서 부패에 관여하는 주요 곰팡이균은 Fusarium sp. 균이 $94.2 \%$ 로 나타났고, 1 $5^{\circ} \mathrm{C}$ 에서는 Botrytis sp. 균이 $65.45 \%$, Fusarium sp. 균이 $27.3 \%$ 로 나타났다. 선박 모의수출 유통 조건인 $5^{\circ} \mathrm{C}$ 에서는 Botrytis sp. 균이 $66.7 \%$, Penicillium sp. 균이 $15.2 \%$, Fusarium sp. 균이 9\% 정도 나타났고, $1^{\circ} \mathrm{C}$ 에서는 Botrytis sp. 균이 $60.4 \%$, Unknown이 $21 \%$, Penicillium sp. 균이 $10.4 \%$, Fusarium sp. 균이 $8.3 \%$ 정도 발생하였다. 수삼의 소포장에서 항공 모의수출 유통 조건인 $25^{\circ} \mathrm{C}$ 에서 발생하는 주요 곰팡이균은 Fusarium sp. 균이 $60 \%$, Botrytis sp. 균이 $36.5 \%$ 로 나타났고, $15^{\circ} \mathrm{C}$ 에서는 Botrytis sp. 균이 $87.5 \%$, Fusarium sp. 균이 $7.14 \%$ 나타났다. 선박 모의수출 유통 조건에서는 Botrytis sp. 균이 $65.8 \%$, Fusarium sp. 균이 $30.4 \%$ 였으며, $1{ }^{\circ} \mathrm{C}$ 에서는 Botrytis sp. 균이 $67.9 \%$, Fusarium sp. 균이 $26.8 \%$, Penicillium sp. 균이 $1.78 \%$ 로 나타났다. 이와 같은 결과에서 수삼의 곰팡이에 의한 부패균은 일반적 으로 Fusarium sp.와 Botrytis sp. 균이 관여함을 알 수 있었 고, 상온 $25^{\circ} \mathrm{C}$ 에서 우점종은 Fusarium sp. 균이며 $15^{\circ} \mathrm{C}$ 이하

$25^{\circ} \mathrm{C}$

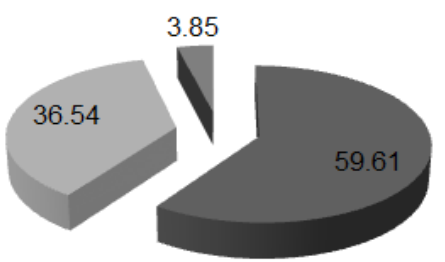

-Fusarium $\quad$ Botrytis $=$ Unknown

$5^{\circ} \mathrm{C}$

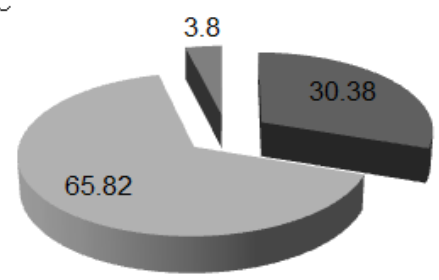

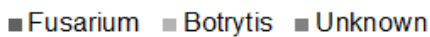

의 온도에서는 Botrytis sp. 균이 수삼 부패에 우세한 종임을 알 수 있었다. 인삼 재배에서 가장 큰 제한요인은 식물병이 고, 그 중 가장 큰 피해를 미치는 것은 인삼 뿌리썩음병으로 알려져 있다. 인삼의 뿌리썩음을 일으키는 병원체는 세균, 선충, 곰팡이 등이 있으며, 그중에서 곰팡이류에 의해서는 Fusarium solani와 Cylindrocarpon destructans에 의한 뿌리 썩음이 가장 많은 피해를 보이고 있고, 세균에 의한 뿌리썩 음병은 주로 Erwinia carotovora에 의한 연부병(soft rot)이 라고 Lee(18)는 보고하였다. 인삼 잿빛곰팡이병원균은 1976년 처음으로 Botrytis cinerea로 보고되었고 이 균은 기주범위가 넓은 다범성균으로 각종 식물에 잿빛곰팡이병 을 일으키며 2차적으로 저장, 수송, 판매중의 과일, 채소류 에 발생하여 큰 피해를 일으킨다고 하였다. 또한 식물이 죽거나 노쇠한 부위에서 발병되기 시작하여 일단 발병되면 병원균의 생육적온이 아니더라도 병이 진전된다고 하였다. Cho 등(19)은 인삼 잿빛곰팡이병균 B. cinerea의 균학적 특성을 조사한 연구에서 B. cinerea의 균핵을 관찰한 결과 병원성 균주는 표면이 주름지고 거칠다고 하였으며, 균핵 형성은 $5-20^{\circ} \mathrm{C}$ 암흑 상태에서 양호하다고 보고하였다.

\section{요 약}

봄수확 수삼의 항공 및 선박의 모의수출 유통 중 손실 유형을 조사하기 위해 수삼을 기능성 LDPE 필름에 $5 \mathrm{~kg}$ 대포장 또는 $500 \mathrm{~g}$ 소포장으로 포장하고 각기 다른 모의수

$15^{\circ} \mathrm{C}$

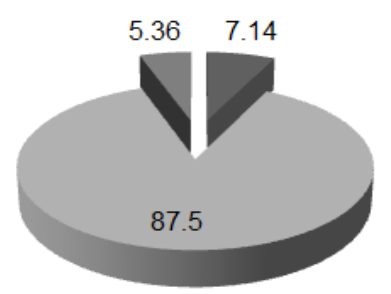

- Fusarium $\quad$ Botrytis $=$ Unknown

$1{ }^{\circ} \mathrm{C}$

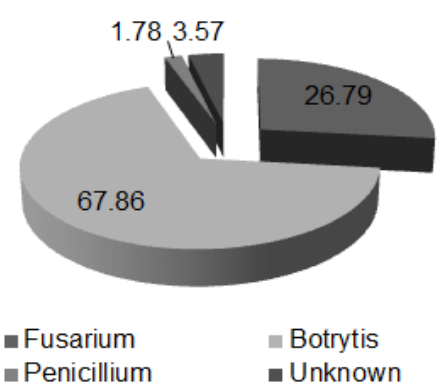

Fig. 9. Fungal strains involved in the loss of fresh ginseng packaged with $500 \mathrm{~g}$ during storage under simulated export conditions and distribution at $10^{\circ} \mathrm{C}$. 
출 유통 온도 및 모의수출 기간 즉 항공 모의수출 유통은 $15^{\circ} \mathrm{C}$ 와 $25^{\circ} \mathrm{C}$ 로 설정된 저장고에 4 일 동안 저장하고, 선박 모의수출 유통은 $1^{\circ} \mathrm{C}$ 와 $5^{\circ} \mathrm{C}$ 로 설정된 저장고에 14 일 동안 저장한 뒤 유통실험을 위해 최종 $10^{\circ} \mathrm{C}$ 로 설정된 저장고에 수삼을 옮기고 수삼의 품질 변화를 조사하였다. 수삼의 품 질 조사는 포장단계부터 $10^{\circ} \mathrm{C}$ 유통기간까지 총 기간 수행하 였다. 조사결과 수삼의 유통 중 손실률에 가장 크게 영향을 미치는 것은 물러짐과 곰팡이 발생에 의한 부패로 나타났 다. 물러짐과 곰팡이에 의한 부패를 합한 종합 손실률에서 손실률 $20 \%$ 를 유통한계 기간으로 정했을 때 항공 모의수출 유통 조건인 $25^{\circ} \mathrm{C}$ 에서 $5 \mathrm{~kg}$ 대포장은 10 일, $500 \mathrm{~g}$ 소포장은 6-7일에 $20 \%$ 에 도달했으며, $15^{\circ} \mathrm{C}$ 는 $5 \mathrm{~kg}$ 대포장은 17 일, $500 \mathrm{~g}$ 소포장은 12-13일에 20\%에 도달했다. 선박 모의유통 조건인 $5^{\circ} \mathrm{C}$ 는 $5 \mathrm{~kg}$ 대포장은 21 일, $500 \mathrm{~g}$ 소포장은 28 일 경에 $20 \%$ 에 도달했고, $1^{\circ} \mathrm{C}$ 는 $5 \mathrm{~kg}$ 대포장은 24 일, $500 \mathrm{~g}$ 소포장은 29 일 경에 $20 \%$ 에 도달하는 것으로 나타나 수삼의 유통은 모의수출 유통 방법뿐 아니라 포장용량도 손실률에 상당한 영향을 미치는 것으로 나타났다. 수삼의 부패에 관 여하는 병원균 중 곰팡이 균은 대부분 Fusarium sp., Botrytis sp., Penicillium sp. 균들로 동정되었고, $25^{\circ} \mathrm{C}$ 에서는 Fusarium sp. 균이 우세종이고, 그 이하의 온도에서는 Botrytis sp. 균이 우세종으로 나타났다.

\section{감사의 글}

본 연구는 농촌진흥청 기관고유사업(No. PJ01260502)의 지원을 받아 수행되었다.

\section{References}

1. Kim JB, Kim NK, Lim JH, Kim SI, Kim HH, Song JY, Kim HG (2009) Environment friendly control of gray mold, a ginseng storage disease using essential oils. Res Plant Dis, 15, 236-241

2. Kim EJ, Kim GH, Kim DM (2007) Effect of surface washing treatment on quality of fresh ginseng during storage. Korean J Food Sci Technol, 39, 380-385

3. Jeon BS, Park CK, Kim NM, Park MH, Chang KS (1998) Effect of controlled atmosphere and modified atmosphere storage on the color and sensual properties of fresh and red ginseng. J Ginseng Res, 22, 82-90

4. Yun SD, Lee SK (2005) High $\mathrm{CO}_{2}$ controlled atmosphere storage of Korean ginseng roots. J Korean Soc Hortic Sci, 46, 18-20

5. Ke D, Goldstein L, O’Mahony M and Kader AA (1991)
Effects of short-term exposure to low $\mathrm{O}_{2}$ and high $\mathrm{CO}_{2}$ atmospheres on quality attributes of strawberries. J Food Sci, 56, 50-54

6. Kim JH, Koo NS, Kim EH, Sohn HJ (2002) Changes in sensory characteristics and chemical constituents of raw ginseng roots individually packaged in a soft film during storage. J Ginseng Res, 26, 145-150

7. Sohn HJ, Kim EH, Lee SK, Nho KB (2001) Quality change and weight loss of fresh ginseng individually packaged in a soft film according to its storage condition. J Ginseng Res, 25, 122-126

8. Sohn HJ, Kim EH, Nho KB, Jung KS, Kim JH (2001) Influence of physical property of soft film and packaging method on the storage stability of individually packaged fresh ginseng. J Ginseng Res, 25, 45-52

9. Kim HS, Kim GH, Kim DM (2011) Effect of low storage temperature on quality of fresh ginseng. Korean J Food Preserv, 18, 459-466

10. Chang JK, Kim CS, Nho KB, Cho BG (2005) Effects of storage conditions on weight loss and free sugar composition of fresh ginseng. J Ginseng Res, 29, 113-118

11. Park MH, Shin YS, Kim SJ, Kim JG (2013) Effect of 1-methylcyclopropene treatment on extension of freshness and storage potential of fresh ginseng. Korean J Hortic Sci Technol, 31, 308-316

12. Kim SI, Sung BJ, Kim HH, Hwang YS (2011) Marketing of cleaned fresh ginseng and pre-packaging fumigation of 2-phenylethyl alcohol on ginseng storability. CNU J Agric Sci, 38, 205-212

13. Kim HH, Hwang YS, Seoung BJ, Kim SI, Cho JW, Kim CS (2006) Distribution characteristics and status of fresh ginseng in Keumsan area. CNU J Agric Sci, 33, 129-140

14. Nelson PE, Toussoun TA, Marasas WFO (1983) Fusarium species: An illustrated manual for identification. The Pennsylvania State University Press, University park, Pennsylvania, USA, p 193

15. Nirenberg H (1976) Untersuchungen uber die morphologische und biologische differenzierung in der fusarium sektion liseola. Mitt Biol Bundesanst Land-u Forstwirtsch, Berlin, Germany, p 1-117

16. Gerlach W, Nirenberg H (1982) The genus Fusarim : A pictorial atlas. Paul Parey, p 406

17. Costa C, Lucera A, Conte A, Mastromatteo M, Speranza B, Antonacci A, Del Nobile MA (2011) Effects of passive and active modified atmosphere packaging conditions on ready-to-eat table grape. J Food Eng, 102, 115-121

18. Lee SG (2004) Fusarium species associated with ginseng 
(Panax ginseng) and their role in the root-rot of ginseng plant. Res Plant Dis, 10, 248-259

19. Cho HS, Jeon YH, Do GR, Cho DH, Yu YH (2008)
Mycological characteristics of Botrytis cinerea causing gray mold on ginseng in Korea. J Ginseng Res, 32, 26-32 